http://dx.doi.org/10.12775/szhf.2020.019

\author{
Mateusz KlonowsKi \\ Nicolaus Copernicus University in Toruń \\ E-MAIL: MATEUSZ.KLONOWSKI@UMK.PL \\ ORCID: 0000-0001-8616-9189 \\ Rafat Palczewski \\ Nicolaus Copernicus University in Toruń \\ E-MAIL: RPALCZ@UMK.PL \\ ORCID: 0000-0001-7368-8094
}

\title{
Epistemic Contextualism and Positional Logic
}

\section{Introduction}

Epistemic contextualism is a widely discussed position that spans both epistemology and the philosophy of language, and according to this position, epistemic sentences (their content or logical value) depend on contextually determined epistemic standards. This paper proposes a formalisation of this position with regard to positional logics, as conceptualised by Jerzy Łoś. ${ }^{1}$

${ }^{1}$ See Jerzy Łoś, "Podstawy analizy metodologicznej kanonów Milla" (Basics of methodological analysis of Mill's canons), Annales Universitatis Mariae Curie-Skłodowska (Lublin, 1947), 2.5. F, 269-301; Jerzy Łoś, "Logiki wielowartościowe a formalizacja funkcji intensjonalnych" (Multivalued logics and formalisation of intensional functions), Kwartalnik Filozoficzny XVII, 1-2 (1948): 59-78. 
The paper is divided into two main parts. Part one, which comprises section 2, outlines epistemic contextualism, i.e., its characteristic thesis, types and modifications, and highlights the main fields of discussion. Subsequently, two related issues are presented: epistemic contextualism as an antisceptical strategy and the context shifting argument. We identify the initial postulates that the formalisation of this position should fulfil.

Part two, ranging from sections 3 to 5 , focuses on the issue of the formalisation of epistemic contextualism. In section 3, we describe two approaches to contextual epistemic logic as a kind of modal logic. In section 4 , we briefly outline the history of positional logic, i.e., the logic of Łośs operator; we also examine the system of minimal realisation, which is a suitable starting point for the analysis of positional systems. In section 5, we present the approach to contextual epistemic logic as a kind of positional logic. Finally, section 6 provides a short summary of our considerations and defines directions for further research.

\section{Epistemic Contextualism}

Epistemic contextualism is a position on the borderline between epistemology and the philosophy of language. It took full shape in the 1980s and 1990s but only became the subject of extensive discussions at the beginning of the $21^{\text {st }}$ century. In this section, we will briefly discuss the main thesis of contextualism, identify the different types of contextualism, present contextualism's antisceptical strategy, and the basic argument for contextualism, also known as the context shifting argument. We will focus only on these elements of contextualist theory that can be used in its formalisation.

\subsection{The Main Thesis of Contextualism: Types and Modifications}

Epistemic contextualism is usually presented as a very general semantic thesis. According to this position, sentences that attribute propositional knowledge (sentences such as " $s$ knows that $p$ ") are contextually dependent, i.e., 
their content or logical value depends on the conversational context (the context of an attributor). This dependence is seen as characteristic, i.e., concerning the verb "know" and not the other components of the sentence. Essential elements of the context are epistemic standards related to the verb "know", which indicate how strong the epistemic position of the agent of knowledge (the subject of the epistemic sentence) should be in relation to a given proposition in order for the sentence related to the proposition to be true.

Epistemic standards and the epistemic position can be modelled in different ways within specific theories of knowledge, with these concepts linked to the assumed definition of knowledge. They are most often linked to the condition of the non-accidental connection of belief and truth, which, within the classical definition of knowledge, refers to the justification condition or modifications thereof. ${ }^{2}$ Contextual theories of knowledge were suggested in the works by DeRose, Cohen, Lewis, and Heller, ${ }^{3}$ among others.

Contextualism can be understood in a much broader manner depending on (among other things) the interpretation of the word "context" as well as its "placement». The word context is obviously ambiguous and we will not attempt to list all its different meanings here. In epistemological and semantic discussions, with regard to sentences about propositional knowledge (more broadly, all propositional attitudes), one may indicate the context related to the circumstances in which the subject of the epistemic sentence (context of the agent), the context of the person forming the epistemic sentence (context of the attributor) and the context of the person who evaluates the epistemic sentence in terms of logical values (context of the assessor) are located.

2 Contextualists, therefore, assume that the concept of knowledge is not primary or indefinable or at least does not boil down to the factivity of knowledge or its relationship with belief. Here, we will not decide whether or not this assumption is necessary for contextual theories.

3 Keith DeRose, "Solving the sceptical problem", The Philosophical Review 104, 1 (1995): 1-52; Keith DeRose, The Appearance of Ignorance (Oxford: OUP, 2017); Stewart Cohen, "How to be a fallibilist", Philosophical Perspectives 2 (1988): 91-123; David Lewis, "Elusive knowledge", Australasian Journal of Philosophy 74, 4 (1996): 549-567; Mark Heller, "The proper role for contextualism in an anti-luck epistemology”, Philosophical Perspectives 13 (1999): 115-129. 
Epistemic contextualism, in a narrow sense, i.e., according to the general characteristics given above, is related to the context of the attributor. The context of the subject, on the other hand, is related to various theories of knowledge, which aim at the degettierization of knowledge (especially Gettier-like situations that point to certain aspects of the environment of the agent of knowledge, e.g., the fake barn scenario posited by Goldman ${ }^{4}$ ). Its role is, therefore, recognised by epistemologists and is sometimes taken into account when analysing the concept of knowledge. However, some researchers include practical circumstances in the context of the subject, i.e., the stake to which the epistemic agent of knowledge is subjected. ${ }^{5}$ Such a position is quite confusingly named practical invariantism or "invariantism", as it emerged mainly in opposition to epistemic contextualism. ${ }^{6}$

The context of assessment (evaluation, assessor) was introduced into semantics by relativism. ${ }^{7}$ As MacFarlane pointed out, this context is as intuitive as that of the attributor: the latter is a possible situation of using a sentence while the former is a possible situation of evaluating a sentence in terms of truth. In semantics (or post-semantics, using MacFarlane's term), an epistemic sentence is true as used in context $c_{1}$ and evaluated in context $c_{2}$. It takes two forms: content relativism and truth-value relativism. ${ }^{8}$

Accepting the role of a given context, or in the case of epistemic contextualism, the context of the attributor, the issue of where to position it within the theory of epistemic sentences - their syntax, semantics or pragmatics - remains

4 See Alvin I. Goldman, "Discrimination and Perceptual Knowledge", The Journal of Philosophy 73, 20 (1976): 771-791.

5 The meaning of "stake" here is ambiguous - it is understood as everything that affects the matter that is important for the epistemic agent. Note that a person may not be aware of the stake or may misjudge it, and this applies to both the epistemic agent and the attributor or assessor.

6 See John Hawthorne, Knowledge and lotteries (Oxford: Clarendon Press, 2004); Jason Stanley, Knowledge and Practical Interests (Oxford: Clarendon Press, 2005).

7 See John MacFarlane, "The assessment sensitivity of knowledge attributions", in: Oxford Studies in Epistemology, vol. 1, eds. Tamar Szabo Gendler, John Hawthorne (Oxford: OUP, 2005): 197-233; John MacFarlane, Assessment Sensitivity: Relative Truth and its Applications (Oxford: OUP, 2014).

8 See Andy Egan, John Hawthorne, Brian Weatherson, "Epistemic modals in context", in: Contextualism in Philosophy. Knowledge, Meaning, and Truth, eds. Gerhard Preyer, Peter Georg (Oxford: OUP, 2005), 131-168. 
to be determined. Epistemic contextualism, in its standard form, is a semantic thesis; however, invariantists argue that contextualism leads to pragmatic conclusions at most, i.e., those related to the use of epistemic sentences with the warranted assertability, and not the truth, conditions.

However, even if we were to presume that we are dealing with a semantic thesis, it must be stressed that contextualism can assume two general forms, according to MacFarlane: indexical and non-indexical contextualism. The former indicates that the content of an epistemic sentence depends on the context (and, hence, its extension or logical value) and the latter indicates that only the extension of an epistemic sentence depends on the context. ${ }^{9}$ These differences are not significant when we face the task of formalising contextualism because for logic, logical values are important and their change is postulated in both approaches.

Epistemic contrastivism is an interesting syntactic attempt to explain contextual intuition. ${ }^{10}$ According to this position, sentences of propositional knowledge are structured as follows: " $s$ knows that $p$ and not $q$ " where $q$ is a contrastive proposition in relation to $p .{ }^{11}$ Hence, for instance, when, in a given situation, we say about someone that "He knows he's drinking Coke", our utterance is inaccurate as such a sentence is elliptical. What we actually mean is that while he is able to distinguish the taste of this drink from many others, such as Fanta, he may not be able to judge whether it is the original Coke or whether it is Pepsi and not Coke. In such a situation, a sentence such as "He knows he's drinking Coke and not Fanta" is true but the sentence "He knows he's drinking Coke and not Pepsi” is false.

9 Such a division is more universal, i.e. it does not refer only to epistemic sentences, but is applicable to all contextually dependent language expressions.

${ }^{10}$ See Jonathan Schaffer, "From contextualism to contrastivism", Philosophical Studies, 119, 1-2 (2004): 73-103; Jonathan Schaffer, "Contrastive knowledge", in: Oxford Studies in Epistemology, vol. 1, eds. Tamar Szabo Gendler, John Hawthorne (Oxford: OUP, 2005), 236-271.

11 For each proposition $p$ there are, in fact, many contrastive propositions, so the question arises of whether the subject has different types of knowledge (one for each contrastive proposition) or rather one type for the whole set of these propositions - in this case, we should include the whole set rather than one proposition in the structure of epistemic sentences. 
Two factors are worth emphasising here. First, the thesis of contextualism, under certain conditions, can be extended to other types of sentences about knowledge: knowledge-wh (i.e., erotetic knowledge or knowledge with an interrogative pronoun: knowledge-when, knowledge-what, knowledge-why, knowledge-who, and so on), knowledge-how (practical knowledge, usually highlighted - not only because of a different notation of the pronoun - as a type of erotetic knowledge), knowledge by acquaintance or objectual knowledge (know $+\mathrm{NP})$ and group knowledge (collective and non-collective), both propositional as well as of the types mentioned above.

Second, the thesis of epistemic contextualism can be absorbed by a broader contextual position wherein a wide or even common contextual dependence of natural language expressions is seen. Within it, it is possible, but not necessary, to introduce epistemic standards as one of the factors that determine the content (or truth conditions) of epistemic sentences. Contextualists who follow this approach often use context shifting arguments (cf. \$2.4).

In this way, we obtain a whole spectrum of contextual positions in a broad sense, and a separate term can be coined to reflect their nature - variantism. This informs an explicit contrast: variantism (for a given type of context, i.e., subject, attributor or assessor) versus invariantism. Each form of variantism may take on further forms depending on the placement of the contextual mechanism (syntax, semantics, pragmatics) or its range (types of epistemic sentences, group/social knowledge). Although we will focus on epistemic contextualism emphasising the role of the context of the attributor later in the paper, positioning it in semantics and limiting ourselves to individual propositional knowledge allows us to see that our formal analyses can also be applied to other forms of variantism, including contrastivism, subject contextualism and relativism.

\subsection{Main Areas of Discussion Regarding Contextualism}

The discussion on the legitimacy of epistemic contextualism is highly developed and covers various areas of philosophical research, the most important ones including the following:

(1) The application of contextualism as a strategy to solve epistemological problems, especially the contemporary form of Cartesian scepticism 
in addition to the Gettier problem, the lottery, easy knowledge, ${ }^{12}$ and so on. ${ }^{13}$

(2) A description and explanation of the semantic mechanism that underlies the general thesis of contextualism, in particular, the indication of the group of contextually dependent expressions the verb "to know" belongs to and possibly a description of the mechanism characteristic of this verb. ${ }^{14}$

(3) The examination of the thesis of contextualism with respect to the methodology of experimental philosophy, i.e., conducting surveys and, on their basis, verifying the extent to which a given philosophical thesis (here, epistemic contextualism) finds confirmation in ordinary intuitions. ${ }^{15}$

(4) The issue of the conclusiveness of the more important arguments for epistemic contextualism, especially context shifting arguments (e.g., WAM) and the epistemic theory of assertion argument. ${ }^{16}$

(5) Problems of contextualism related to a general thesis of semantics - the context of the contextualist, the reduction of the thesis to another position as well as the issue of explanatory power compared to competitive approaches (e.g., relativism). ${ }^{17}$

12 The Gettier problem is commonly known, while the problem of lottery has been very well introduced in a book by John Hawthorne (see Hawthorne, Knowledge and Lotteries) and the problem of easy knowledge in an article by Stewart Cohen (see Stewart Cohen, "Basic knowledge and the problem of easy knowledge", Philosophy and Phenomenological Research 65, 2 (2002): 309-329).

13 Cf. e.g., Cohen, "How to be a fallibilist": 91-123; Lewis, "Elusive knowledge": 549-567.

${ }^{14}$ Cf. e.g., Cohen, "How to be a fallibilist": 91-123; Stanley, Knowledge and Practical Interests.

15 Cf. e.g., Wesley Buckwalter, "Knowledge isn't closed on Saturday: A study in ordinary language", Review of Philosophy and Psychology 1, 3 (2010): 395-406; Emmanuel Chemla, Nat Hansen, "Experimenting on contextualism", Mind \& Language 28, 3 (2013): 286-321.

16 Cf. e.g., Keith DeRose, The Case for Contextualism (Oxford: OUP, 2009); Hawthorne, Knowledge and Lotteries.

17 See e.g., Jesper Kallestrup, "Contextualism between scepticism and common-sense", Grazer Philosophische Studien 69 (2005): 247-253; MacFarlane, Assessment Sensitivity: Relative Truth and Its Applications. 
(6) The formalisation of epistemic contextualism, which is most often an introduction to standard epistemic logic. ${ }^{18}$

The thematic areas mentioned above are vaguely demarcated but often overlap or even condition one another. For instance, research within the framework of experimental philosophy (3) is mainly conducted in relation to the conclusiveness of the context shifting argument (4), and the discussions conducted in the area mentioned in point (4) are crucial because if we do not have arguments in favour of adopting contextualism, then looking for a semantic mechanism (2) is unfounded. In this case, solving epistemological problems (1), if at all effective to some extent, would be arbitrary.

However, solutions developed in one area may be independent of findings from other areas. For instance, one may be a contextualist with regard to "knowing", i.e., highlighting a particular semantic mechanism of contextual sensitivity and, simultaneously, taking the position that contextualism is not applicable to epistemological problems (some or all).

In this paper, we attempt to formalise contextualism, recognising that positive results in this area of research, although not considered a direct argument for the legitimacy of contextualism, can show that it can be consistently presented and unquestionably modelled. Further, we propose a formalisation within a framework different than that of epistemic logic, one understood as modal logic with an epistemic interpretation of functors.

At this juncture, it is worth pointing out the first postulate of an adequate formalisation of contextualism: the factivity of knowledge should be preserved within it. In fact, contextualism has been accused of contradicting this principle, fundamental to the theory of knowledge, according to which knowledge entails truth (in other words, only those propositions that are true

18 Cf. e.g., Manuel Rebuschi, Franck Lihoreau, “Contextual epistemic logic”, in: Dialogues, Logics and Other Strange Things, eds. Cedric Degremont, Laurent Keiff, Helge Rueckert (London: College Publications, 2008), 305-335; Franck Lihoreau, Manuel Rebuschi, "Reasoning about knowledge in context", in: Interdisciplinary Works in Logic, Epistemology, Psychology and Linguistics. Dialogue, Rationality, and Formalism, eds. Manuel Rebuschi, Martine Batt, Gerhard Heinzmann, Franck Lihoreau, Michel Musiol, Alain Trognon (Cham, Heidelberg, New York, Dordrecht, London: Springer, 2014), 155-179. 
can be the object of knowledge). ${ }^{19}$ Although this allegation has been directly rebutted, ${ }^{20}$ the formalisation of contextualism wherein we maintain the factivity of knowledge provides an indirect response.

\subsection{Contextualism as an Anti-Sceptical Strategy}

Contextualism was developed as a position during the discussion on the contemporary form of Cartesian scepticism. ${ }^{21}$ This form of scepticism starts with the formulation of a hypothetical scenario wherein our knowledge of the outside world is partly (local scepticism) or entirely (global, Cartesian scepticism) undermined. ${ }^{22}$ Let us consider global scepticism, for instance, based on the hypothesis of brains in a vat or an evil demon. ${ }^{23}$ The reasoning of the sceptic is as follows: (GSH - global sceptical hypothesis, $\mathrm{p}$ - any proposition about the outside world that would be false if the GSH were to occur):

1. $s$ does not know that not-GSH.

2. If $s$ knows that $\mathrm{p}$, then $s$ knows that not-GSH.

3. Thus, $s$ does not know that $\mathrm{p}$.

19 See e.g., Peter Baumann, "Contextualism and the factivity problem", Philosophy and Phenomenological Research 76, 3 (2008): 580-602. The factivity of knowledge has become the subject of an extensive dispute today due to the work by Allan Hazlett (Allan Hazlett, "The myth of factive verbs", Philosophy and Phenomenological Research 80, 3 (2010): 497-522), but it is still widely accepted as the least controversial component of knowledge theory (see also, Rafał Palczewski, "O aletycznej naturze wiedzy" ("On the alethic nature of knowledge"), Filozofia Nauki 23, 1 (2015): 99-145).

${ }^{20}$ See e.g., Anthony Brueckner, Christopher T. Buford, "Contextualism, SSI and the factivity problem", Analysis 69, 3 (2009): 431-438.

21 See Stewart Cohen, "Knowledge, context, and social standards", Synthese 73, 1 (1987): 3-27; Stewart Cohen, "How to be a fallibilist": 91-123; DeRose, "Solving the sceptical problem": 1-52; Lewis, "Elusive knowledge": 549-567.

22 Local doubt can only be a stage in global doubt, and localness understood that way can also be described as Cartesian. Dretske's works were a point of reference for Cohen and DeRose, wherein local scepticism, presented with the famous zebra example, played an important role.

${ }^{23}$ The globality of the hypothesis may refer to one or all the senses and may concern a reality that is external or internal to the agent, e.g., corporeality (sense of the body) or emotional states. Thus, global hypothesis does not mean that it is maximal in the sense that it undermines everything that can be challenged - it is not entirely clear where the limits of doubt can be placed here. The term is, therefore, ambiguous, but in connection with a particular story told by a sceptic, it gains certain distinct features. 
In contrast to the sceptic is the dogmatist, who accepts premise 2 but whose starting point is the denial of the sceptic's conclusion, i.e., the sentence " $s$ knows that $\mathrm{p}$ ", and who finishes with the denial of the sceptic's premise 1 , i.e., the sentence " $s$ knows that not-GSH".

Yet another strategy is presented by the opponent of the deductive closure of knowledge. ${ }^{24}$ This opponent undermines premise 2 and, thus, challenges both the sceptic's and dogmatist's arguments. However, the goal is that of antiscepticism - the preservation of the knowledge of the outside world as it has been to date.

The contextualist proposes a different view that preserves, as it were, the partial intuitions associated with each of the three previous strategies. The legitimacy of the deductive closure of knowledge is preserved, but it is relativised to the conversational context, or more precisely, the context of the epistemic standards adopted by the attributor. In a sceptical context, therefore, the reasoning of the sceptic is conclusive. Thus, we do not know that $p$, and in all non-sceptical contexts (more precisely, without global sceptic hypotheses), the reasoning of a dogmatist is conclusive - not only do we know that $p$ but we also know that not-GSH.

The contextual strategy is debatable but we will not attempt to respond to the accusations levelled against it here. From the point of view of formalisation, one component is important: the preservation of the deductive closure of knowledge in one or more forms. Therefore, we accept the second postulate of an adequate formalisation of contextualism: knowledge is reducible in relation to the implications. ${ }^{25}$

${ }^{24}$ See e.g. Fred Dretske, “Epistemic operators", The Journal of Philosophy 67, 24 (1970): 1007-1023.

25 One needs to emphasise two factors here. First, the combination of step 2 in the sceptic's argumentation with the deductive closure of knowledge is not entirely clear. It does not just pertain to the actual form of scepticism - most often, it is assumed that we are looking at the epistemic equivalent of the modal axiom $(\mathrm{K})$ but it also concerns whether step 2 is a consequence of its adoption (see Maria Lasonen-Aarnio, "Contextualism and closure", in: The Routledge Handbook of Epistemic Contextualism, ed. Jonathan Jenkins Ichikawa (London and New York: Routledge, 2017), 156-167). Second, it is not out of the question for someone to reject the deductive closure of knowledge and, at the same time, adopt contextualism, such as Mark Heller (see Mark Heller, "The proper role for contextualism in an anti-luck epistemology", Philosophical Perspectives 13 (1999): 115-129). However, such a combination is not standard and is challenging. 


\subsection{Context Shifting Arguments}

The response of contextualism to the problem of scepticism is, in fact, a special case of the main argument that is aimed to facilitate the adoption of contextualism, which we will refer to, using Cappelen's and Lepore's terms, ${ }^{26}$ as the context shifting argument. Generally speaking, this type of argument is based on the formulation of a thought experiment wherein two or more almost identical situations (contexts) are described. In one of them, a given epistemic sentence is considered true, and in the other, the same epistemic sentence is negated. ${ }^{27}$

There are various instances of its particular form in the literature that differ not only in the scenario (the story described in the thought experiment) on which the argument is based but also in the epistemic attributes of the scenario: they are formulated in the first or third person singular. The differences may seem unimportant but can affect the intuitions that contextualists want to evoke. Importantly, there are additional pragmatic implications associated with the first-person sentences. ${ }^{28}$

Let us consider the context shifting argument for the verb "know" presented by DeRose. ${ }^{29}$ The argument is based on the description of a situation wherein a third-person attribution occurs. The description has been shortened here with the key elements preserved:

The office. Thelma, Louise and Lena were friends working in the same office. One day, when they all had a day off, they agreed to have lunch together in the town. Prior to that, they decided to drop by the office to collect their pay checks

26 See e.g., Herman Cappelen, Ernie Lepore, “Context shifting arguments", Philosophical Perspectives 17 (2003): 25-50.

27 Contextualists do not provide factual situations to illustrate this mechanism; therefore, they do not formulate empirical confirmation, which may raise some doubts. Some philosophers have conducted surveys on the thought experiments of contextualists within the framework of experimental philosophy. However, it is difficult to accept that survey research can replace the assertion that such situations have occurred.

${ }_{28}$ As is usually the case, instead of attributing knowledge to oneself, we merely make a given proposition. We say, "I know that..." when we want to emphasise the importance of information, dispel someone's doubts, and so on. These observations may also be linked to the epistemic standard of assertion.

29 See DeRose, The Case for Contextualism. 
and also because Thelma and Lena had made a bet with a few of their colleagues for a token amount of one dollar that John, who is usually absent from work, would finally show up. As they walked towards John's office, they saw his hat and coat hanging next to the door. They also heard a conversation with the following sentence in it: "Go and talk to John before you send this letter".

The three friends left the office satisfied - after all, they had taken their pay checks and two of them had won the bet. After lunch together, Thelma went to the pub to meet her friends while Louise and Lena went home, each their own way.

At the pub, Thelma met a friend from work, one of those with whom she had made a wager about John's presence in the office. She said that John had been in the office because she had seen his things and heard a conversation about him, which indicated that he was present. The colleague acknowledged his lost wager and gave Thelma a dollar. Remembering that he still had a wager with Lena, he asked, "Does Lena know if John was at work?" Thelma replied, "Yes, she does, she was with me".

Meanwhile, Louise was confronted by police in front of her house. An important investigation into a serious crime was underway. The most important factor in this case was whether John had been in the office that day. The police said they had no reason to believe that he was not at work but they wanted confirmation of his presence. Louise admitted that she had only seen his things and heard a part of the conversation but had not met John and, thus, could not guarantee that he had been at work (therefore, Louise accepted the situation where John's things were at work and someone was talking about his presence but he was not at work as possible). The response to the question "Does Lena know if John was at work?" was "No, she doesn't. She was there with me and did not see John, only his things".

Let us assume that John was at work, Thelma's utterance at the pub and Louise's utterance to the police were made at exactly the same time and that Lena was on her way home at the time, thinking about things completely unrelated to her work, the wager or John. In this scenario, Thelma's context is LOW (with low epistemic standards) and Louise's context is HIGH (with high epistemic standards). If we agree that the described situation does not contain disturbing or strange elements, it leads us to consider both utterances of epistemic sentences, i.e., Thelma's and Louise's, as being true. 
The contextualist's argument would, therefore, appear as follows:

(1) Thelma's assertion "[Lena] knows, [that John was at work today]" is true in LOW.

(2) Louise's assertion "[Lena] does not know, [if John was at work today]" is true in HIGH.

(3) Thelma's assertion in LOW and Louise's in HIGH are said at exactly the same time.

(4) The best explanation of the truth of (1)-(3) is that in LOW and HIGH, we are dealing with different epistemic standards, which influence the differences in the truth conditions of epistemic sentences and their extension.

(5) Hence, the example of The Office testifies to the truth of the thesis of contextualism.

The argument is abductive in nature. Point (4) refers to three alternative semantic interpretations of the first two premises: 1) in LOW and HIGH, the assertions are false; 2) in LOW, Thelma's assertion is true, while in HIGH, Louise's assertion is false; 3 ) in LOW, Thelma's assertion is false and in HIGH, Louise's assertion is true. According to the contextualist, all these alternatives are less intuitive or have undesirable consequences. ${ }^{30}$

However, we must consider what constitutes epistemic standards in this scenario. How does the difference between the situations described in the scenario affect the truth of the epistemic sentences? Two factors are usually highlighted in this context: the relevant alternatives and the stake, i.e., the practical circumstances that the attributor takes into account. ${ }^{31}$ Louise, not Thelma, considers the possibility of John's absence despite the fact that his things are in the

${ }^{30}$ It is not our task to neutralise all the doubts related to the context shifting argument of the epistemic contextualist, or to present its more accurate form. These issues are discussed, e.g., in Rafał Palczewski, Wiedza w kontekstach, t. I: Między pragmatyką a semantyką (Toruń: Wydawnictwo Naukowe UMK, 2014), chapter 3.

${ }^{31}$ If these were actual practical circumstances that would concern the subject of the epistemic attribution, but would not be known to the attributor, the contextualism does not take them into account in such a situation - their role is emphasised, as we mentioned in $\$ 2.1$, by practical invariantism (contextualism of the subject). It should also be added that in addition to relevant alternatives or stake, the role of other contextual factors such as accommodation rules can be emphasised for the semantics of epistemic sentences. 
office and he is spoken of as if he were present. In addition, a one-dollar wager is certainly not a high stake when compared to providing information to the police. It is these two elements, or even one of them, according to contextualists, that are responsible for the fact that the assertions by Thelma and Louise are perceived as true even though they exclude each other.

We, therefore, accept another postulate of utmost importance in relation to the factors that determine epistemic standards: the formalisation of contextualism should account for relevant alternatives as well as practical circumstances. In other words, the concept of context should be general enough to allow for the stake and possibly other factors.

\section{Epistemic Contextualism in Modal Logic}

In the section below, we will briefly describe the two formalisations of epistemic contextualism expressed in the language of modal logic. In both cases, we deal with a static and dynamic approach. The logics closed under the Gödel rule are considered in both cases and, therefore, the problem of logical omniscience arises. Finally, both use the notion of relevant alternatives; this notion will also be applied in our formalisation.

\subsection{Contextual Epistemic Logic}

Lihoreau and Rebuschi ${ }^{32}$ introduced two types of contextual epistemic logic. The first is a modification of the multimodal logic $\mathbf{S 5}$ and the second is a modification of the dialogical multimodal logic S5. Let us focus on the logic of the first type, Contextual Epistemic Logic (CEL).

32 Rebuschi, Lihoreau, “Contextual epistemic logic”, 305-335. 
The presentation of CEL is preceded by a discussion of the various descriptions of the concept of knowledge, which are the foundation of the four ways of interpreting the knowledge operator discussed in the paper. The introduced formalisation is defined based on the theory of relevant alternatives (or RA theory). According to RA theory, in order to know $\varphi$, all relevant alternatives to $\varphi$ must be excluded. By a relevant alternative, we should understand a possible world whose point of view we consider important for determining the value of a given sentence to express some potential knowledge. Thus, the interpretation of standard epistemic logic, according to which knowledge requires the verification of truth in the worlds not eliminated by the agent, is complemented by the point of view of the relevant worlds.

In order to represent context with regard to epistemic logic, according to Lihoreau and Rebuschi, ${ }^{33}$ we can use one of the following:

1. Non-standard models, i.e., place the context in the metalanguage and evaluate each (standard epistemic) formula relatively to some world and context;

2. Standard models with a standard modality within an extension from the basic modal logic;

3. Standard models with a non-standard interpretation for context modalities.

The first possibility is described by referring to the contextual model, which we will discuss below. The second one is also briefly described and refers to a kind of hybrid logic - we will skip this item. The main aim of Lihoreau and Rebuschi's ${ }^{34}$ work is to analyse the third possibility, which we will outline by referring to the CEL logic.

A contextual model is an extension of the multi-S5-model (a model of multimodal logic S5) $\left\langle W,\left\{Q_{j}\right\}_{j \in J}, V\right\rangle$, where $J \neq \varnothing$, with the set $C=\left\{c_{i} \mid i \in I\right\}$, for a $\varnothing \neq I \subseteq J$, and the function of a relevant context $R: C \times W \rightarrow P(W)$. Based on this model, the following proposals of truth condition for the $K_{j} \varphi$ formula are defined:

33 Ibidem, 38.

34 Ibidem. 


$$
\begin{aligned}
& c_{i}, w \vDash K_{j} \varphi \text { iff } \forall_{w^{\prime} \in W}\left(\text { if } w Q_{j} w^{\prime} \text { and } w^{\prime} \in R\left(c_{i}, w\right) \text {, then } c_{i}, w^{\prime} \vDash \varphi\right) \\
& c_{i}, w \vDash K_{j} \varphi \text { iff } \forall_{w^{\prime} \in W}\left(\text { if } w Q_{j} w^{\prime} \text { and } w^{\prime} \in R\left(c_{i}, w\right) \text {, then } c_{j}, w^{\prime} \vDash \varphi\right) \\
& c_{i}, w \vDash K_{j} \varphi \text { iff } \forall_{w^{\prime} \in W}\left(\text { if } w Q_{j} w^{\prime} \text { and } w^{\prime} \in R\left(c_{j}, w\right) \text {, then } c_{i}, w^{\prime} \vDash \varphi\right) \\
& c_{i}, w \vDash K_{j} \varphi \text { iff } \forall_{w^{\prime} \in W}\left(\text { if } w Q_{j} w^{\prime} \text { and } w^{\prime} \in R\left(c_{j}, w\right) \text {, then } c_{j}, w^{\prime} \vDash \varphi\right) .
\end{aligned}
$$

The given possibilities of interpretation correspond to different concepts of knowledge. Interpretation (1.1), depending on the properties imposed on the function of the relevant context, is intended to correspond to scepticism or anti-scepticism, interpretation (1.2) to contextualism and interpretation (2.2) to subjectivism.

Let us now proceed to the description of logic CEL. The language of logic CEL is a modification of the language of modal logic obtained through the introduction of the context formulas, which are intended to represent contexts. Unlike the contextual model, in this case, the context is represented at the level of the objective language and not the metalanguage. The set At of context formulas is the smallest set $\Sigma$ such that:

- $\mathrm{T}, \perp \in \Sigma$

- if $\varphi \in \operatorname{Var}$, then $\varphi, \neg \varphi \in \Sigma$

- if $\varphi, \psi \in \Sigma$, then $\varphi, \neg \varphi \in \Sigma$

where Var is a countable set of propositional variables. For a given set of $I$ and $J \subseteq I$, the set of formulas is the smallest set $\Sigma$ such that:

- $\operatorname{Var} \subseteq \Sigma$

- if $\varphi, \psi \in \Sigma$, then $\neg \varphi,(\varphi \wedge \psi) \in \Sigma$

- if $j \in J$ and $\varphi \in \Sigma$, then $K_{j} \varphi \in \Sigma$

- if $i \in I, c_{i} \in$ At and $\varphi \in \Sigma$, then $(\varphi)^{c_{i}} \in \Sigma .{ }^{35}$

Formula $(\varphi)^{c_{i}}$ may be understood as $c_{i} \rightarrow \varphi$. The arrow $\rightarrow$ is to be understood as having material implication. In the given language, the implication can be defined by means of negation and conjunction in a standard way.

${ }^{35}$ Note that for the given set of formulas, there is an inverse relationship between sets of indexes, which differs from the contextual model. 
A CEL-model is the multi-S5-model. In this case, no additional relativisation points are introduced, as the context is represented at the language level by means of context formulas. The truth conditions of formulas built with negation $\neg$, conjunction $\wedge$ and knowledge operator $K_{j}$, respectively, are standard. In the case of a formula of the form $(\varphi)^{c_{i}}$, where $\varphi=\neg \psi$ or $\varphi=\psi \wedge \chi$, the following condition is assumed:

$$
w \vDash(\varphi)^{c_{i}} \text { iff } w \not c_{i} \text { or } w \vDash \varphi .
$$

If $\varphi=K_{j} \psi$, the following interpretations are considered, corresponding to interpretations (1.1), (1.2), (2.1) and (2.2) as defined on the basis of the contextual model:

$$
\begin{aligned}
& w \vDash\left(K_{j} \psi\right)^{c_{i}} \text { iff } w \vDash c_{i} \text { or } w \vDash K_{j}(\psi)^{c_{i}} \\
& w \vDash\left(K_{j} \psi\right)^{c_{i}} \text { iff } w \vDash c_{i} \text { or } w \vDash K_{j}(\psi)^{c_{j}} \\
& w \vDash\left(K_{j} \psi\right)^{c_{i}} \text { iff } w \vDash c_{j} \text { or } w \vDash K_{j}(\psi)^{c_{i}} \\
& w \vDash\left(K_{j} \psi\right)^{c_{i}} \text { iff } w \vDash c_{j} \text { or } w \vDash K_{j}(\psi)^{c_{j}} .
\end{aligned}
$$

The given definition of a set of formulas and the given truth conditions indicate that the logic CEL can be understood as a kind of theory based on the logic S5. It is easy to see what Lihoreau and Rebuschi point out ${ }^{36}$ - for any CEL-formula $\varphi$, there is S5-formula $\varphi^{\prime}$ such that for any multi-S5-model and any world $w, w \vDash \varphi$ iff $w \vDash \varphi^{\prime}$.

\subsection{The Problem of Closure under Known Implication}

Halliday ${ }^{37}$ formalised two types of RA theories, referring to the discussion between Dretske and Lewis on the problem of accepting a knowledge closure under known implication (i.e., the closure of knowledge under the Modus Ponens rule, usually expressed by the modal axiom $(\mathrm{K})$ ). Dretske's RA the-

${ }^{36}$ Rebuschi, Lihoreau, "Contextual epistemic logic", 316.

37 Wesley H. Halliday, "Epistemic logic, relevant alternatives, and the dynamics of context", in: New Directions in Logic, Language and Computation, eds. Daniel Lassiter, Marija Slavkovik (Berlin, Heidelberg: Springer, 2012), 109-129. 
ory rejects the closure of knowledge under known implication, while the RA theory accepted by Lewis indicates the acceptance of a closure under Modus Ponens. In Lewis's view, Dretske's analysis of closure under known implication does not account for a change of context, which affects a set of relevant worlds and on account of which axiom (K) should be accepted.

In order to illustrate the problem of the closure of knowledge under known implication, Halliday introduces the following example:

Medical Diagnosis. Suppose that two medical students A and B are subjected to a test. Their professor introduces them to the same patient, who presents various symptoms, and the students are to make a diagnosis. After some independent investigation, both students conclude that the patient has a common condition $c$. They are both correct. However, only $\mathbf{A}$ passes the test, as the professor wished to see if the students would check for another common condition $c^{\prime}$, which causes the same visible symptoms as $c$. While $\mathbf{A}$ ran laboratory tests to rule out $c^{\prime}$ before making the diagnosis, $\mathbf{B}$ made the diagnosis after only a physical exam.

[...] In this case, B is lucky. The patient did have the condition B associated with the patient's visible symptoms, but if the professor had chosen a patient with $c^{\prime}$, student B might have misdiagnosed them. By contrast, $\mathbf{A}$ secured against this possibility of error by running lab tests. For this reason, the professor judged that $\mathbf{A}$ knew that the patient's condition was $c$ and the latter therefore passed the test.

Of course, A did not secure against every possibility of error. Suppose there is an extremely rare disease $x$ such that patients with $x$ appear to have $c$ on the lab tests given for $c$ and $c^{\prime}$ even though people with $x$ are immune to $c$ and only extensive further testing can detect $x$ in its early stages. Can we say, then, that $\mathbf{A}$ did not know that the patient had $c$ after all since $\mathbf{A} \operatorname{did}$ not rule out $x$ ? $^{38}$

Referring to example Medical diagnosis, let us assume that $\mathbf{A}$ knows that if his patient has condition $c$, he does not have $x$, i.e., (i) $K(c \rightarrow \neg x)$. However, $\mathbf{A}$ has not tested for $x$, so it cannot be said with certainty that he knows that his patient does not have $x$, i.e., (ii) $\neg K \neg x$. At the same time, however, $\mathbf{A}$ knows that the patient has $c$, i.e., $K c$ (iii). So, we have to reject (iv) $(K c \wedge K(c \rightarrow \neg x)) \rightarrow K \neg x$.

38 See ibidem, 109-110. 
Halliday points out that in order to maintain (iv), we can either challenge (iii) (since $\mathbf{A}$ has not ruled out condition $x$ ) or assume that (ii) is false (A may know that $\neg x$ without conducting tests, e.g., based on medical literature, he knows it is $c$ and excludes $x$ ). The adoption of the first solution, according to Halliday, leads to radical scepticism, and the adoption of the second is associated with the acceptance of the easy knowledge. ${ }^{39}$

On the basis of the RA theory with Dretske's approach, we reject (iv). A did not rule out a relevant alternative wherein the patient has $x$. On the basis of the RA theory with Lewis's approach, i.e., contextual theory, we accept (iv). A does not need to exclude an alternative wherein the patient has $x$ because it is irrelevant in the initial context, i.e., before there is a possibility that the patient has the rare condition $x$. Accepting such a possibility leads to a change of context. According to Lewis, we cannot accept (iii) in this new context and, therefore, we accept (iv). Thus, we obtain a contextual interpretation of the situation described by Halliday in line with the contextual antisceptical strategy described in section 2.3 (more broadly, the context shifting argument described in section 2.4). ${ }^{40}$

Lewis's approach, therefore, indicates the dependence of the relevance of the alternatives on the change of context. This interpretation shows that the context changes with the change of sentences that are meant to express the content of potential knowledge. Thus, the relevance of the alternatives is dependent on the content of potential knowledge.

39 This corresponds to our description of contextual strategy in section 2.3: easy knowledge is only a consequence of the dogmatism indicated there.

${ }^{40}$ Let us note that Halliday completely omitted describing the stake as he dealt with the theory of relevant alternatives and its contextual version and not contextualism in general. Of course, we can only assume that the health of the patient was the stake, but if it was a random patient completely unknown to the characters in this scenario, then such a stake is normal in doctors' work. We can raise the stake by indicating that the patient is a person from the professor's immediate family. Will such an assumption strengthen the professor's assessment of the students' knowledge? Not every contextualist would answer in the affirmative; the role of the stake is also questioned in some X-phi studies. However, in section 2.4, we assumed, for the sake of simplicity, that this is a factor that affects the truth conditions of epistemic sentences. In other words, it is good to have a formalisation that allows other factors that determine epistemic standards. 
Halliday ${ }^{41}$ presents two ways to formally represent contextual knowledge based on two approaches to modal operators, i.e., statically (in the language of standard epistemic logic) and dynamically (appropriately extending the language of standard epistemic logic with new modalities). In each approach, he gives the interpretations of the knowledge operator according to the approaches of Dretske and Lewis (there is also an interpretation that refers to the analysis by Descartes). On this basis, he determines the relationships and differences between the described theories of Dretske and Lewis. In the case of the static approach, the $\mathbf{T}$-model (the model of modal logic $\mathbf{T}$ ) $\langle W, Q, V\rangle$ is extended by the function, which assigns to every alternative $w$ a relation $\preceq_{w} \subseteq W_{w} \times W_{w}$, for $W_{w} \subseteq W$ such that:

- $\preceq_{w}$ is reflexive and transitive

- for all $u \in W_{w}, w \preceq_{w} u$.

The given relation $\preceq_{w}$ is intended to allow the comparison of alternatives in terms of contextual relevance, i.e., $\preceq_{w} t$ can be read as: $u$, which is at least as relevant (at $w$ ) as $t$. It should be emphasised that in the given approach, the $Q$ relation is understood in a particular way, i.e., $u Q t$ should be read as: $u$, which is an uneliminated alternative for the agent in $t$.

In order to determine the interpretation of the knowledge operator (motivated by the Dretske and Lewis approaches, respectively), Halliday uses a set of minimal elements of subset $S \subseteq W$ determined by the relation of being the more relevant alternative:

$$
\begin{aligned}
& t \preceq_{w} u \text { iff } t \preceq_{w} u \text { and } \sim u \preceq_{w} t \\
& \operatorname{Min}_{\unlhd_{w}}(S)=\left\{w \in S \cap W_{w} \mid \sim \exists_{t \in S} t \preceq_{w} u\right\} .
\end{aligned}
$$

Halliday defines the set $\operatorname{Min}_{\leq_{w}}(S)$ as the set of the most relevant (at $w$ ) alternatives out of those in $S$ ordered by $\preceq_{w}$. In his analysis, he considers only models and relations $\preceq_{w}$ that guarantee a non-emptiness of set $\operatorname{Min}_{\unlhd_{w}}(S)$ for any non-empty $S \subseteq W_{w}$. In addition, Halliday introduces the following set notations:

${ }^{41}$ Halliday, "Epistemic logic, relevant alternatives, and the dynamics of context", 109-129. 


$$
\begin{aligned}
& \llbracket \varphi \rrbracket=\{w \in W \mid w \vDash \varphi\} \\
& \overline{\llbracket \varphi \rrbracket}=W \backslash \llbracket \varphi \rrbracket .
\end{aligned}
$$

The proposals for the truth condition of epistemic expressions are as follows:

(C-condition)

(D-condition)

(L-condition)

$$
\begin{aligned}
& w \vDash K \varphi \text { iff } \forall u(\text { if } u \in \llbracket \varphi \rrbracket, \text { then } \sim w Q u) \\
& w \vDash K \varphi \text { iff } \forall u\left(\text { if } u \in \operatorname{Min}_{\unlhd_{w}}(\overline{\llbracket \varphi \rrbracket}), \text { then } \sim w Q u\right) \\
& w \vDash K \varphi \text { iff } \forall u\left(\text { if } u \in \operatorname{Min}_{\unlhd_{w}}(W) \cap \overline{\llbracket \varphi \rrbracket}, \text { then } \sim w Q u\right) .
\end{aligned}
$$

(C-condition) is another form of the standard truth condition for the epistemic expression. (D-condition) implies that the agent knows that $\varphi$ in the case every (maximally) relevant alternative from those in which $\varphi$ is false is rejected by the agent. In turn, (L-condition) allows us to state that the agent knows that in the case every (maximally) relevant alternative of all the alternatives, wherein, additionally, $\varphi$ is false, it is rejected by the agent.

It is worth noting that the static approach by Halliday, like that of Lihoreau and Rebuschi, cannot be accepted for agents without logical omniscience. The logics they define are closed under Gödel's rule. ${ }^{42}$

Later in our considerations, we will use the concept of relevant alternatives, modifying the aforementioned approaches. Unlike Halliday, Lihoreau and Rebuschi, we will express the knowledge operator with Łośs operator, and for this purpose, we will define the required positional logics. In this way, we will draw attention to the possibility of using tools other than modal logic in the analysis of epistemic contextualism, especially since Łošs operator had already been used in epistemic logic before the use of modal operators.

${ }^{42}$ It is obvious for the logic CEL. The logics analysed by Halliday, on the other hand, are closed under (RE):

$$
\frac{\varphi \leftrightarrow \psi}{K \varphi \leftrightarrow K \psi}
$$

and contain the formula $(\mathrm{N})$ :

$K \top$ 


\section{4. Łośs Realisation Operator and Positional Logic}

In 1947, Jerzy Łoś $^{43}$ proposed the first ever system of temporal logic. Łośs ideas were presented in Polish, and their translation in English was provided in 1951 by Henryk Hiż. ${ }^{44}$ Łośs proposals regarding temporal logic were further developed by researchers such as Rescher ${ }^{45}$ and Urquhart. ${ }^{46}$ The full picture of his logic as well as its possible modifications, which are useful in the analysis of reasoning containing time variables, was presented by Jarmużek and Tkaczyk. ${ }^{47}$

In order to define temporal logic, Łoś introduced a proposition-creating functor of a name argument and one proposition argument into the language of logic. Such a functor is called Łośs operator or realisation operator $(R)$. The expressions $R_{\alpha} \varphi$ can generally be read as follows: a sentence $\varphi$ is realised in the position $\alpha$. The possibilities of understanding the realisation of a proposition in a given position vary greatly. ${ }^{48}$ In addition to the temporal interpretation of 1947, Łos $^{49}$ proposed an epistemic interpretation of the realisation

43 Łoś, "Podstawy analizy metodologicznej kanonów Milla": 269-301.

${ }^{44}$ Henryk Hiż, "Review: J. Los, Foundations of the methodological analysis of Mill's canons", Journal of Symbolic Logic 16 (1951): 58-59.

45 Nicholas Rescher, “Topological logic”, in: Nicholas Rescher, Topics in philosophical logic (Dordrecht: D. Reidel Publishing Company, 1968), 229-249.

46 Nicholas Rescher, Alasdair Urquhart, Temporal Logic (Vienna: Springer, 1971).

47 Marcin Tkaczyk, Tomasz Jarmużek, "Jerzy Łoś positional calculus and the origin of temporal logic", Logic and Logical Philosophy 28 (2019): 259-276. Cf. Tomasz Jarmużek, "Minimal logical systems with R-operator: Their meta-logical properties and ways of extensions", in: "Perspectives on Universal Logic" 2007, eds. J. Bezieau, A. Costa-Leite, Polimetrica Publisher, 319-333; Tomasz Jarmużek, On Sea Battle Tomorrow That May Not Happen. A Logical and Philosophical Analysis of the Master Argument (Berlin: Peter Lang, 2018), 209-224; Tomasz Jarmużek, Marcin Tkaczyk, Normalne logiki pozycyjne (Normal Positional Logics) (Lublin: Towarzystwo Naukowe KUL, 2015), 29-72; Marcin Tkaczyk, Logika czasu empirycznego (Logic of Physical Time) (Lublin, Wydawnictwo KUL, 2009).

48 Various intensional interpretations of the realisation operator were presented by Jarmużek, Minimal logical systems with R-operator: Their meta-logical properties and ways of extensions.

49 Łoś, "Logiki wielowartościowe a formalizacja funkcji intensjonalnych”: 59-78. 
operator in 1948. He thus defined the first system of epistemic logic. ${ }^{50}$ In this case, the expression $R_{\alpha} \varphi$ can be read as follows: agent $\alpha$ knows that $\varphi .1948$ work by Łoś was in Polish, and, as in the case of his work from 1947, the ideas were presented in English as early as 1949, this time by Roman Suszko. ${ }^{51}$

Generally, the logic of Łośs operator is called positional logic. ${ }^{52}$ A good starting point for formal positional logic considerations is the Minimal Realisation System (MR logic). Minimal realisation entails accepting the distribution of the realisation operator over the logical connectives. MR logic was first characterised semantically and axiomatically by Jarmużek and Pietruszczak. ${ }^{53}$ Its subsystems, obtained by modifying the set of logical values, were analysed by Tkaczyk. ${ }^{54}$ Its role of strengthening positional logic with quantifiers as well as the possibility of expressing modal operators with regard to such logic was presented by Jarmużek and Tkaczyk. ${ }^{55}$ Recently, an analysis of the extended version of the language of positional logic obtained by adding predicate symbols was presented by Jarmużek and Parol. ${ }^{56}$

50 The first work on the possibility of using modal operators with regard to epistemic logic was published in 1951 by von Wright (Georg von Wright, An Essay in Modal Logic (Amsterdam, North-Holland Publishing Company, 1951).

51 Roman Suszko, "Review: Jerzy Łoś, Many-valued logics and formalisation of intensional functions", Journal of Symbolic Logic 14 (1949): 64-65. The analysis of the epistemic interpretation of the realisation operator was presented in Polish, e.g., in Marek Lechniak, "Logika epistemiczna Jerzego Łosia a teoria racjonalnego zachowania" ("Epistemic logic of Jerzy Łoś and the Theory of rational behavior"), Roczniki Filozoficzne 26, 1 (1988): 79-91. The possibility of the epistemic interpretation of logic with Łośs operator has been discussed in Mateusz Klonowski, Krzysztof Krawczyk, "Problem wszechwiedzy logicznej. Krytyka nienormalnych światów i propozycja nowego rozwiązania" ("The problem of logical omniscience. The critique of non-normal worlds and the proposition of new solution"), Filozofia Nauki 27, 1 (2019): 27-48.

52 See Jarmużek, Tkaczyk, Normalne logiki pozycyjne.

53 Tomasz Jarmużek, Andrzej Pietruszczak, "Completeness of minimal positional calculus", Logic and Logical Philosophy 13 (2004): 147-162.

54 Marcin Tkaczyk, "Negation in weak positional calculi", Logic and Logical Philosophy 22 (2013): 3-19. Cf. Tkaczyk, Logika czasu empirycznego.

${ }_{55}$ In Tomasz Jarmużek, Marcin Tkaczyk, "Expressive Power of Positional Operator R: A Case Study in Modal Logic and Modal Philosophy", Ruch Filozoficzny LXXV, 2 (2019): 93-107 as well as in Tomasz Jarmużek, Marcin Tkaczyk, Normalne logiki pozycyjne, 168-192.

56 Tomasz Jarmużek, Aleksander Parol, "On some language extension of logic MR: A semantic and tableau approach", Roczniki Filozoficzne 68 (2020), 345-366. 
The possibility of the epistemic interpretation of Łośs operator proposed in 1948 is important for our purposes. Additionally, it is important to take into account the interpretation proposed by Malinowski, Pietrowicz and Szalacha-Jarmużek. ${ }^{57}$ In accordance with the approach presented by them, the realisation operator can be used to analyse the reasoning concerning the social phenomena. To this end, the realisation operator should be modified by replacing the name constant by a tuple of individual constants. Such a tuple can allow for the representation of a complex social context in which the realisation of these or other states of affairs is found..$^{58}$ In this way, we can account for the perspective of any finite number of agents, obtaining a multiagent systems analysis tool. For instance, in order to include an infinite number of agents, we could replace a tuple of individual constants with an infinite sequence of name constants. However, when studying multi-agent systems, the perspective of a finite number of agents is usually taken into account.

Combining Łośs epistemic interpretation ${ }^{59}$ with the context-dependent interpretation by Malinowski, Pietrowicz and Szalacha-Jarmużek, ${ }^{60}$ we will describe the possibility of using the realisation operator in the analysis of epistemic contextualism. Within this analysis, the expression $R_{\alpha} \varphi$ can be read as follows: in the context $\alpha$ the agent knows that $\varphi$. Thus, unlike in the work Logiki wielowartościowe a formalizacja funkcji intensjonalnych (Multivalued logics and formalisation of intensional functions) by Łoś, the name constant does not refer to the agent but to the context, as proposed in Logic of social ontology and Łośs operator by Malinowski, Pietrowicz and SzalachaJarmużek. On the other hand, unlike in Logic of social ontology and Łoś's operator, we maintain the epistemic interpretation of the realisation operator first suggested in Logiki wielowartościowe a formalizacja funkcji intensjonalnych.

57 Jacek Malinowski, Krzysztof Pietrowicz, Joanna Szalacha-Jarmużek, "Logic of social ontology and Łošs operator", Logic and Logical Philosophy 29 (2020): 239-258.

${ }^{58}$ Cf. Dana Scott, "Advice on modal logic", in: Philosophical Problems in Logic, ed. K. Lambert (Dordrecht: Reidel, 1970), 148-150; Jarmużek, On Sea Battle Tomorrow That May Not Happen. A Logical and Philosophical Analysis of the Master Argument, 29-34.

59 Łoś, "Logiki wielowartościowe a formalizacja funkcji intensjonalnych": 59-78.

${ }^{60}$ Malinowski, Pietrowicz, Szalacha-Jarmużek, "Logic of social ontology and Łośs operator": 239-258. 


\subsection{The MR Logic}

Within the interpretation we propose, we will refer to the language and models of MR. Therefore, we briefly describe MR below. Let Var = $=\left\{p, q, r, p_{1}, q_{1}, r_{1}, \ldots\right\}$ be a countable infinite set of propositional variables. The $L_{\mathbf{C P L}}$ language is the language of classical propositional logic and is defined in the following manner:

$$
L_{\mathbf{C P L}}=\langle\operatorname{Var},\{\neg, \wedge, \mathrm{V}, \rightarrow\},\{(,)\}\rangle .
$$

The set of formulas in $L_{\mathbf{C P L}}$ is defined in a standard manner and denoted as $L_{\mathbf{C P L}}$. Let Con $=\left\{a, b, c, a_{1}, b_{1}, c_{1}, \ldots\right\}$ be a countable infinite set of individual constants. The language of positional $\operatorname{logic}\left(L_{\mathbf{P}}\right)$ is the language $L_{\mathbf{C P L}}$ extended with Łoś's realisation operator:

$$
L_{\mathbf{P}}=\left\langle\operatorname{Var},\{\neg, \wedge, \vee, \rightarrow\},\left\{R_{\alpha} \varphi \mid \alpha \in \operatorname{Con}\right\},\{(,)\}\right\rangle .
$$

The set of $\mathbf{M R}$ formulas in $L_{\mathbf{P}}$ is the smallest set $\Sigma$ such that:

- if $\varphi \in L_{\mathrm{CPL}}$, then $R_{\alpha} \varphi \in \Sigma$

- if $\varphi \in \Sigma$, then $\neg \varphi \in \Sigma$

- if $\varphi, \psi \in \Sigma$, then $(\varphi \wedge \psi),(\varphi \vee \psi),(\varphi \rightarrow \psi) \in \Sigma$.

In the notation of MR formulas (as well as in the case of other formulas), we will omit the outer brackets. We will also use the following abbreviation $\varphi \leftrightarrow \psi=(\varphi \rightarrow \psi) \wedge(\psi \rightarrow \varphi)$, where $\varphi, \psi$ are the elements of a given set of formulas. The set of $\mathbf{M R}$ formulas in $L_{\mathbf{P}}$ is denoted as $L_{\mathbf{M R}}$. Let us note that in the set $L_{\mathbf{M R}}$, the formulas $L_{\mathbf{C P L}}$ are present only in the scope of the realisation operator, and no iteration of the realisation operator will occur.

A model of $\mathbf{M R}$ logic (or an $\mathbf{M R}$ model) is an ordered triple $\mathfrak{M}=\langle W, f, V\rangle$ such that:

- $W$ is a non-empty set of positions

- $f:$ Con $\rightarrow W$ is a denotation function that assigns position to individual constants 
- $V: W \times L_{\mathbf{C P L}} \rightarrow\{1,0\}$ is a classical valuation of formulas relativised to elements from $W$, i.e., for any position $w \in W$ and any formulas $\varphi, \psi \in L_{\mathbf{C P L}}$

$$
\begin{aligned}
& V(w, \neg \varphi)=1 \text { iff } V(w, \varphi)=0 \\
& V(w, \varphi \wedge \psi)=1 \text { iff } V(w, \varphi)=V(w, \psi)=1 \\
& V(w, \varphi \vee \psi)=1 \text { iff }(V(w, \varphi)=1 \text { or } V(w, \psi)=1) \\
& V(w, \varphi \rightarrow \psi)=1 \operatorname{iff}(V(w, \varphi)=0 \text { or } V(w, \psi)=1)
\end{aligned}
$$

The concept of a true formula in an MR model $\mathfrak{M}$ is set in a standard manner while maintaining the classic meaning of logical connectives. In the case of formulas built with the help of the realisation operator, we assume that, $\mathfrak{M} \vDash R_{\alpha} \varphi$ iff $v(f(\alpha), \varphi)=1$.

The MR logic is a logic defined in relation to the class of MR models. The relation $\vDash \subseteq P\left(L_{\mathbf{M R}}\right) \times L_{\mathbf{M R}}$ is defined in a standard manner by means of the notion of truth in a model. The formula $\varphi$ is MR-valid iff $\varnothing \vDash_{\mathbf{M R}} \varphi$. We say that the rule with premises $\varphi_{1}, \ldots, \varphi_{n}$ and conclusion $\psi$ is MR-valid iff if $\varphi_{1}, \ldots, \varphi_{n}$ are $\mathbf{M R}$-valid, then $\psi$ is $\mathbf{M R}$-valid.

By virtue of the conditions $\left(\mathrm{v}_{1}\right)-\left(\mathrm{v}_{4}\right)$, we can easily state that the realisation operator meets the conditions of distribution over the logical connectives. In the case of negation, we have $R_{\alpha} \neg \varphi \leftrightarrow \neg R_{\alpha} \varphi$ which is MR-valid for any $\varphi \in L_{\mathbf{C P L}}$. In the case of the binary connective $* \in\{\Lambda, \vee, \rightarrow\}$, we have $R_{\alpha}(\varphi * \psi) \leftrightarrow\left(R_{\alpha} \varphi * R_{\alpha} \psi\right)$ which is MR-valid for any $\varphi, \psi \in L_{\mathbf{C P L}}$. Moreover, for any $\varphi \in L_{\mathbf{C P L}}, R_{\alpha} \varphi$ is MR-valid if $\varphi$ is the tautology of classical propositional logic (or CPL-valid).

\section{Epistemic Contextualism on the Basis of Positional Logic}

The language of epistemic logic must allow for iterations of the epistemic operator and the occurrence of formulas that do not contain an epistemic operator or we would not be able to consider such issues as the factivity of knowledge or the self-knowledge of the epistemic agent. Therefore, we need to extend the set of formulas $L_{\mathbf{M R}}$ of the MR logic. Let us consider a set of 
formulas defined in the language $L_{\mathbf{P}}$ in a standard manner, i.e., as the smallest set $\Sigma$ such that:

- if $\varphi \in$ Var, then $\varphi \in \Sigma$

- if $\varphi \in \Sigma$, then $\neg \varphi \in \Sigma$

- if $\varphi, \psi \in \Sigma$, then $(\varphi \wedge \psi),(\varphi \vee \psi),(\varphi \rightarrow \psi) \in \Sigma$

- if $\varphi \in \Sigma$ and $\alpha \in$ Con, then $R_{\alpha} \varphi \in \Sigma$.

Let us denote the resulting set as $L_{\mathbf{P}}$. Such a set contains both the $L_{\mathbf{C P L}}$ formulas outside the scope of the realisation operator and the iterations of the realisation operator. Of course, the set also contains $L_{\mathbf{M R}}$. In this case, the $R_{\alpha} \varphi$ expression can be read as follows: in the context $\alpha$, the agent knows that $\varphi$.

In order to give the realisation operator a contextual-epistemic interpretation, we introduce the following modifications to an MR model:

- First, set $W$ will constitute a non-empty universe of contexts, which means that positions from set $W$ will represent different contexts. ${ }^{61}$

- Second, we extend the MR model with a family of relations $\left\{Q_{\varphi}\right\}_{\varphi \in L_{\mathbf{P}}}$. For any $\varphi \in L_{\mathbf{P}}, Q_{\varphi} \subseteq W \times W$ is a relation of the relevant context (determined relative to $\varphi$ ). If the relation $u Q_{\varphi} t$ occurs, we will state that $t$ is the relevant context relative to $u$ by virtue of $\varphi$.

- Third, the function of valuation $V: W \times L_{\mathbf{P}} \rightarrow\{1,0\}$ is to satisfy the conditions $\left(\mathrm{v}_{1}\right)-\left(\mathrm{v}_{4}\right)$ and the following condition for any context $u \in W$, any formula $\varphi \in L_{\mathbf{P}}$ and any $\alpha \in$ Con:

$$
V\left(u, R_{\alpha} \varphi\right)=1 \text { iff }\left(u Q_{\varphi} f(\alpha) \text { and } V(f(\alpha), \varphi)=1\right) .
$$

The given condition $\left(\mathrm{v}_{5}\right)$ means that with a given context $u$, the agent in context $\alpha$ knows $\varphi$ in the case when the following conditions are met:

- $f(\alpha)$ is a relevant context relative to $u$ by virtue of $\varphi$;

$-\varphi$ is true in the context $f(\alpha)$.

${ }^{61}$ Let us emphasise that we do not determine the components of a context. Although we subsequently use the concept of relevance, it may mean not only a relevant alternative, which is what we most often write about for the sake of simplicity, but also a relevant stake, i.e., practical circumstances. Thus, the third postulate of the adequate formalisation of epistemic contextualism, which was adopted at the end of section 2 , is satisfied. 
Let us also note that the condition $\left(\mathrm{v}_{5}\right)$ makes it possible to determine the value of formulas containing the iteration of the realisation operator, eliminating, in a way, successive occurrences of the realisation operator.

- Fourth, we introduce to the model a distinguished-in- $W$ context $w$.

The resulting model is an ordered quadruple $\left\langle W, f,\left\{Q_{\varphi}\right\}_{\varphi \in L_{\mathbf{P}}}, V, w\right\rangle$ and shall be called a positional contextual model. We denote the class of all positional contextual models by $\mathcal{C}$. The notion of a truth in a positional contextual model is defined by means of valuation $V$ in the distinguished context $w$, i.e., $\mathfrak{M} \vDash \varphi$ iff $V(w, \varphi)=1$.

For any class $M \subseteq \mathcal{C}$, the consequence relation $\vDash_{M} \subseteq P\left(L_{\mathbf{P}}\right) \times L_{\mathbf{P}}$ is defined in the standard manner by means of the notion of truth in a positional contextual model. Formula $\varphi$ is $M$-valid iff $\emptyset \vDash_{M} \varphi$. We will state that the rule with the premises $\varphi_{1}, \ldots, \varphi_{n}$ and the conclusion $\psi$ is $M$-valid iff if $\varphi_{1}, \ldots, \varphi_{n}$ are $M$-valid, then $\psi$ is $M$-valid.

A positional contextual model resembles a possible-world model in some respects, differing mainly because the former contains the denotation function, and makes it possible to define a specific truth condition ( $\left.\mathrm{v}_{5}\right)$. Moreover, in our view, the elements of the model domain play the role of contexts. Therefore, there is a difference as compared to the approach proposed by Lihoreau and Rebuschi ${ }^{62}$ and Halliday. ${ }^{63}$ Additionally, instead of an accessibility relation, we have a family of relations between contexts indexed by formulas, as in the case of models for the conditional logic proposed by Stalnaker and Lewis, as per Chellas's approach. ${ }^{64}$

The relation of the relevant context relation we introduced requires further observation. As we noted in section 3, the concept of relevant alternatives is usually introduced, i.e., worlds whose point of view with regard to $\varphi$ must be taken into account to determine that the agent knows $\varphi$, as part

62 Rebuschi, Lihoreau, "Contextual epistemic logic", 305-335; Lihoreau, Rebuschi, "Reasoning about knowledge in context", 155-179.

${ }^{63}$ Halliday, "Epistemic logic, relevant alternatives, and the dynamics of context", 109-129.

64 Brian Chellas, "Basic conditional logic", Journal of Philosophical Logic, 4 (1975): 133-153. Cf. Graham Priest, An Introduction to Non-Classical Logic. From If to Is (New York: Cambridge University Press, 2008), 82-101. 
of the formal analysis of epistemic contextualism. ${ }^{65}$ However, in the case of epistemic contextualism, sentences expressing the agent's knowledge are relativised to the given context. It can, therefore, be concluded that it is not so much the point of view of a given world but simply the point of view of a given context that is important to us, or it is simply recognised that the possible world represents context. Thus, when evaluating the logical value of a given sentence, we take into account the given context (the initial context) and then assess whether the context that the agent possesses in a given case is relevant and whether, from the point of view of the agent's context, the sentence is true.

Referring to Halliday's example discussed in section 3, let us consider the context of the professor evaluating $\mathbf{A}$ and $\mathbf{B}$ as the initial context. Each of the students has their own context. A conducts laboratory tests while $\mathbf{B}$ does not. The students make the same diagnosis, i.e., from the perspective of their contexts, the sentence (s) that states that a given patient suffers from a particular condition $c$ is true. However, the context of $\mathbf{B}$ is not relevant with regard to the initial context by virtue of the sentence (s). Thus, the relevance constitutes a kind of sieve that allows us to separate those contexts of the agent where truth makes it possible for us to determine knowledge from those where truth does not guarantee knowledge.

According to the given interpretation of relevance, the particular case of the positional contextual model will be one wherein the context of the evaluator of a given sentence is the context of the agent. Let us consider the model $\left\langle W, f,\left\{Q_{\varphi}\right\}_{\varphi \in L_{\mathbf{P}}}, V, w\right\rangle$ such that for any $\varphi \in L_{\mathbf{P}}, Q_{\varphi} \subseteq W \times W$ is a relation defined in the following manner for any $u, t \in W$ :

$\left(\operatorname{def} Q_{\varphi}\right) \quad u Q_{\varphi} t$ iff $u=t$

Let us note that the model determined by the condition ( $\operatorname{def} Q_{\varphi}$ ) can be identified with an ordered quadruple $\langle W, f, V, w\rangle$, and the condition ( $\left.\mathrm{v}_{5}\right)$ is equivalent to the following:

$$
\left(\mathrm{v}_{5}{ }^{\prime}\right) \quad V\left(u, R_{\alpha} \varphi\right)=1 \text { iff }(f(\alpha)=u \text { and } V(f(\alpha), \varphi)=1) .
$$

${ }^{65}$ Cf. Rebuschi, Lihoreau, “Contextual epistemic logic”, 306-308. 
In the given condition $\left(\mathrm{v}_{5}{ }^{\prime}\right)$, in order to verify the truth of $R_{\alpha} \varphi$, we take into account only such context as is the context of the given agent. In other words, we limit the range of contexts for which something is true for the context of the agent. The described model will be called a contextual (positional) model of the agent. The class of all contextual models of agents is denoted as $\mathcal{A}$.

\subsection{Selected Laws and Rules on the Ground of Positional Contextual Models}

Let us look at the formulas that are valid on the grounds of the given model type and the limitations of the examined models that allow the desired laws to be obtained. Let us consider the distribution rights of the realisation operator specified in language $L_{\mathbf{P}}$, i.e., the formulas of the following forms for any $\varphi, \psi \in L_{\mathbf{P}}$ :
(DN) $\quad R_{\alpha} \neg \varphi \leftrightarrow \neg R_{\alpha} \varphi$
(DC) $\quad R_{\alpha}(\varphi \wedge \psi) \leftrightarrow\left(R_{\alpha} \varphi \wedge R_{\alpha} \psi\right)$
(DD) $\quad R_{\alpha}(\varphi \vee \psi) \leftrightarrow\left(R_{\alpha} \varphi \vee R_{\alpha} \psi\right)$
(DI) $\quad R_{\alpha}(\varphi \rightarrow \psi) \leftrightarrow\left(R_{\alpha} \varphi \rightarrow R_{\alpha} \psi\right)$.

The formulas of the following forms for any $\varphi, \psi \in L_{\mathbf{P}}$ are as follows:

$$
\begin{array}{ll}
\left(\mathrm{K}^{R}\right) & R_{\alpha}(\varphi \rightarrow \psi) \rightarrow\left(R_{\alpha} \varphi \rightarrow R_{\alpha} \psi\right) \\
\left(\mathrm{T}^{R}\right) & R_{\alpha} \varphi \rightarrow \varphi \\
\left(\mathrm{D}^{R}\right) & R_{\alpha} \varphi \rightarrow \neg R_{\alpha} \neg \varphi \\
\left(4^{R}\right) & R_{\alpha} \varphi \rightarrow R_{\alpha} R_{\alpha} \varphi \\
\left(5^{R}\right) & \neg R_{\alpha} \varphi \rightarrow R_{\alpha} \neg R_{\alpha} \varphi .
\end{array}
$$

Of course, $\left(\mathrm{D}^{R}\right)$ and $\left(\mathrm{K}^{R}\right)$ are implied by (DN) and (DI), respectively:

- For any $\varphi \in L_{\mathbf{P}}$ and any $\alpha \in$ Con, $\left(R_{\alpha} \neg \varphi \leftrightarrow \neg R_{\alpha} \varphi\right) \rightarrow\left(R_{\alpha} \varphi \rightarrow \neg R_{\alpha} \neg \varphi\right)$ is $\mathcal{C}$-valid.

- For any $\varphi, \psi \in L_{\mathbf{P}}$ and any $\alpha \in \operatorname{Con},\left(R_{\alpha}(\varphi \rightarrow \psi) \leftrightarrow\left(R_{\alpha} \varphi \rightarrow R_{\alpha} \psi\right)\right) \rightarrow$ $\rightarrow\left(R_{\alpha}(\varphi \rightarrow \psi) \rightarrow\left(R_{\alpha} \varphi \rightarrow R_{\alpha} \psi\right)\right)$ is $\mathcal{C}$-valid. 
In addition, let us focus on verifying $M$-validity where $M \in\{\mathcal{C}, \mathcal{A}\}$ of the counterparts of monotonicity and Godel's rules for any $\varphi, \psi \in L_{\mathbf{P}}$ i $\alpha \in$ Con:

$\left(\mathrm{RM}^{R}\right)$

$$
\frac{\varphi \rightarrow \psi}{R_{\alpha} \varphi \rightarrow R_{\alpha} \psi}
$$

$\left(\mathrm{RG}^{R}\right)$

$$
\frac{\varphi}{R_{\alpha} \varphi}
$$

Considering that every CPL-valid formula is $\mathcal{C}$-valid, the fulfilment of $\left(\mathrm{RG}^{R}\right)$ results in the fact that $\mathcal{C}$-valid is $R_{\alpha} \varphi$ if $\varphi$ is $\mathrm{CPL}$-valid.

The following correlations occur in the case of $C$ class models:

1.1. Formulas of the form $\left(\mathrm{D}^{R}\right)$ are $\mathcal{C}$-valid.

1.2. Formulas of the form (DN), (DC), (DD), $\left(\mathrm{K}^{R}\right),\left(\mathrm{T}^{R}\right),\left(4^{R}\right)$ and $\left(5^{R}\right)$ are not $\mathcal{C}$-valid.

1.3. Neither $\left(\mathrm{RM}^{R}\right)$ nor $\left(\mathrm{RG}^{R}\right)$ is a $\mathcal{C}$-valid rule.

In order to justify 1.1 , let us assume that $V\left(w, R_{\alpha} \varphi\right)=1$. Then, by $\left(\mathrm{v}_{5}\right)$, $V(f(\alpha), \varphi)=1$ and hence, by $\left(\mathrm{v}_{1}\right), V(f(\alpha), \neg \varphi)=0$. Therefore, by $\left(\mathrm{v}_{5}\right)$, $V\left(w, R_{\alpha} \neg \varphi\right)=0$, and, hence, by $\left(\mathrm{v}_{1}\right), V\left(w, \neg R_{\alpha} \neg \varphi\right)=1$.

In order to justify 1.2 and 1.3 , it is sufficient to note that we always block the $\mathcal{C}$ -validity of formulas of the given forms, except for $\left(\mathrm{T}^{R}\right)$, and show that the given formula or rule is not $\mathcal{C}$-valid by specifying the appropriate relations of the relevant context. For instance, when analysing $(\mathrm{DN})$, we may have $V\left(w, R_{\alpha} \varphi\right)=0$, i.e., $V\left(w, \neg R_{\alpha} \varphi\right)=1$, and $V\left(w, R_{\alpha} \neg \varphi\right)=0$ for any $\varphi \in L_{\mathbf{P}}$ and $\alpha \in$ Con. This is so because neither the fact that $V(f(\alpha), \varphi)=0$ nor the non-occurrence of relation $w Q_{\varphi} f(\alpha)$ have to force the occurrence of relation $w Q_{\varphi} f(\alpha)$. In this case, it is enough to consider an empty relation of a relevant context.

In the case of $\left(\mathrm{T}^{R}\right)$, it is important that $V(f(\alpha), \varphi)=1$ does not have to force $V(w, \varphi)=1$, even for $w$ such that $w Q_{\varphi} f(\alpha)$.

The following correlations occur in the case of models from class $\mathcal{A}$ :

2.1. Formulas of the form (DC), (DD), $\left(\mathrm{K}^{R}\right),\left(\mathrm{T}^{R}\right),\left(\mathrm{D}^{R}\right)$ or $\left(4^{R}\right)$ are $\mathcal{A}$-valid.

2.2. Formulas of the form (DN), (DI) and $\left(5^{R}\right)$ are not $A$-valid.

2.3. $\left(\mathrm{RM}^{R}\right)$ is an $\mathcal{A}$-valid rule.

2.4. $\left(\mathrm{RG}^{R}\right)$ is not an $\mathcal{A}$-valid rule. 
Below, we will briefly justify 2.1 and 2.3:

- Ad. (DC) and (DD). We have $V\left(w, R_{\alpha}(\varphi \wedge \psi)\right)=1$, by $\left(\mathrm{v}_{2}\right)$ (resp. $\left(\mathrm{v}_{3}\right)$ and $\left(\mathrm{v}_{5}{ }^{\prime}\right)$, iff $f(\alpha)=w$ and $\left.V(f(\alpha), \varphi)=1\right)$ and $f(\alpha)=w$ and $V(f(\alpha), \psi)=1)(\operatorname{resp} .(f(\alpha)=w$ and $V(f(\alpha), \varphi)=1)$ or $(f(\alpha)=w$ and $V(f(\alpha), \psi)=1))$, by $\left(\mathrm{v}_{5}{ }^{\prime}\right)$, iff $V\left(w, R_{\alpha} \varphi\right)=1$ and $V\left(w, R_{\alpha} \psi\right)=1\left(\right.$ resp. $V\left(w, R_{\alpha} \varphi\right)=1$ or $\left.V\left(w, R_{\alpha} \psi\right)=1\right)$.

- Ad. $\left(\mathrm{K}^{R}\right)$. Suppose that $V\left(w, R_{\alpha}(\varphi \rightarrow \psi)\right)=1$ and $V\left(w, R_{\alpha} \varphi\right)=1$. By $\left(\mathrm{v}_{5}{ }^{\prime}\right) f(\alpha)=w, V(f(\alpha), \varphi \rightarrow \psi)=1$ and $V(f(\alpha), \varphi)=1$. Therefore, by $\left(\mathrm{v}_{4}\right), V(f(\alpha), \psi)=1$. Since $f(\alpha)=w$, by $\left(\mathrm{v}_{5}{ }^{\prime}\right) V\left(w, R_{\alpha} \psi\right)=1$.

- Ad. $\left(\mathrm{T}^{R}\right)$ and $\left(4^{R}\right)$. Suppose that $V\left(w, R_{\alpha} \varphi\right)=1$. By $\left(\mathrm{v}_{5}{ }^{\prime}\right) f(\alpha)=w$ and $V(f(\alpha), \varphi)=1$. Thus, $V(w, \varphi)=1$. Moreover, $f(\alpha)=f(\alpha)$. Therefore, by $\left(\mathrm{v}_{5}{ }^{\prime}\right), V\left(w, R_{\alpha} R_{\alpha} \varphi\right)=1$.

- Ad. $\quad\left(\mathrm{D}^{R}\right)$. Suppose that $V\left(w, R_{\alpha} \varphi\right)=1$. By $\left(\mathrm{v}_{5}{ }^{\prime}\right)$ $f(\alpha)=w$ i $V(f(\alpha), \varphi)=1$. Hence, by $\left(\mathrm{v}_{1}\right), \quad V(f(\alpha), \neg \varphi)=0$. Hence, by $\left(\mathrm{v}_{5}{ }^{\prime}\right)$ and $\left(\mathrm{v}_{1}\right), V\left(w, \neg R_{\alpha} \neg \varphi\right)=1$.

- Ad. $\left(\mathrm{RM}^{R}\right)$. Let us assume that $\varphi \rightarrow \psi$ is $\mathcal{A}$-valid, i.e., for any contextual model of the agent $\mathfrak{M}, \mathfrak{M} \vDash \varphi \rightarrow \psi$, i.e. $V(w, \varphi)=0$ or $V(w, \psi)=1$, where $w$ is the distinguished context in $\mathfrak{M}$. Let us take any model $\mathfrak{M} \in \mathcal{A}$, where $w$ is the distinguished context in $\mathfrak{M}$. Suppose that $V\left(w, R_{\alpha} \varphi\right)=1$. Then, by $\left(\mathrm{v}_{5}{ }^{\prime}\right), f(\alpha)=w$ and $V(f(\alpha), \varphi)=1$. Thus, $V(f(\alpha), \psi)=1$. Therefore, by $\left(\mathrm{v}_{5}{ }^{\prime}\right), V\left(w, R_{\alpha} \psi\right)=1$.

In order to justify 2.2 and 2.4 , let us consider such a model where $f(\alpha)=u$ and $w \neq u$ is the distinguished world. Then:

- Ad. (DN) and (DI). By $\left(\mathrm{v}_{5}{ }^{\prime}\right),\left(\mathrm{v}_{1}\right)$, and since $f(a) \neq w$, we have $V\left(w, \neg R_{a} \varphi\right)=1$ and $V\left(w, R_{a} \neg \varphi\right)=0$. Similarly, since $f(a) \neq w$, we have $V\left(w, R_{a} \varphi \rightarrow R_{a} \psi\right)=1$ and $V\left(w, R_{\alpha}(\varphi \rightarrow \psi)\right)=0$.

- Ad. $\left(5^{R}\right)$. By $\left(\mathrm{v}_{5}{ }^{\prime}\right)$ and since $f(a) \neq w, V\left(w, R_{a} \varphi\right)=0$, i.e., by $\left(\mathrm{v}_{1}\right) \quad V\left(w, \neg R_{a} \varphi\right)=1$. Moreover, by $\left(\mathrm{v}_{5}^{\prime}\right)$, and since $f(a) \neq w$, $V\left(w, R_{a} \neg R_{a} \varphi\right)=0$.

- Ad. $\left(\mathrm{RG}^{R}\right)$. Of course, we have $V(w, \varphi \vee \neg \varphi)=1$. However, by $\left(\mathrm{v}_{5}{ }^{\prime}\right)$, and since $f(a) \neq w$, we also have $V\left(w, R_{a}(\varphi \vee \neg \varphi)\right)=0$.

According to 2.1 and 2.3, the contextual positional models of agents allow us to analyse only such contextually dependent knowledge, which is the following: 
- Closed under Modus Ponens, which is evidenced by $\left(\mathrm{K}^{R}\right)$;

- Closed under positive introspection, which is evidenced by $\left(4^{R}\right)$;

- Closed under the consequence relation, which is evidenced by $\left(\mathrm{RM}^{R}\right)$.

Of course, knowledge should entail truth (factivity of knowledge), as evidenced by $\left(T^{R}\right)$. Therefore, it should also be non-contradictory, as evidenced by $\left(D^{R}\right)$. The analysed models do not force the valid formulas to be a component of knowledge in every context. The $\left(\mathrm{RG}^{R}\right)$ rule is not $\mathcal{A}$-valid. Nevertheless, we can still believe that models with $\mathcal{A}$-valid allow us to obtain an approach to knowledge that is too strong (for instance, if we are interested in analysing contextually dependent knowledge that does not have to be closed under the consequence relation). For this reason, we analyse models from different subclasses of $\mathcal{C}$, which are superclasses of $A$, below.

The following question then arises: Which model limitations are sufficient for the formulas of forms (DC), (DD), $\left(\mathrm{K}^{R}\right),\left(\mathrm{T}^{R}\right)$ or $\left(4^{R}\right)$, which, as previously agreed, we consider acceptable or even required in the formalisation of epistemic contextualism, to become $\mathcal{C}$-valid? Let us consider the following conditions:

$$
\begin{aligned}
& \text { if } u Q_{\varphi} t \text {, then } u Q_{\psi} t \text {, where } \psi \text { is a subformula of } \varphi \\
& \text { if } u Q_{\varphi} t \text { and } u Q_{\psi} t \text {, then } u Q_{\varphi \wedge \psi} t \\
& \text { if } u Q_{\varphi} t \text { or } u Q_{\psi} t \text {, then } u Q_{\varphi \vee \psi} t \\
& \text { if } u Q_{\varphi \rightarrow \psi} t \text { and } u Q_{\varphi} t \text {, then } u Q_{\psi} t \\
& \text { if } u Q_{\varphi} t \text { and } V(t, \varphi)=1 \text {, then } V(u, \varphi)=1 \\
& \text { if } u Q_{\varphi} t \text {, then } u Q_{R_{\alpha} \varphi} t \text {. }
\end{aligned}
$$

We can see that for any context model $\mathfrak{M}$, the following correlations occur:

- if $\mathfrak{M}$ satisfies (c1), (c2), then formulas of the form (DC) are true in $\mathfrak{M}$;

- if $\mathfrak{M}$ satisfies (c1), (c3), then formulas of the form (DD) are true in $\mathfrak{M}$;

- if $\mathfrak{M}$ satisfies (c4), then formulas of the form $\left(\mathrm{K}^{R}\right)$ are true in $\mathfrak{M}$;

- if $\mathfrak{M}$ satisfies (c5), then formulas of the form $\left(\mathrm{T}^{R}\right)$ are true in $\mathfrak{M}$;

- if $\mathfrak{M}$ satisfies (c6), then formulas of the form $\left(4^{R}\right)$ are true in $\mathfrak{M}$. 
Finally, we will consider a certain correlation. Let us assume the following conditions:

$$
\begin{aligned}
& \text { if } u Q_{\varphi} t \text {, then } \forall_{s \in W}\left(u Q_{\varphi} s \text { iff } t Q_{\varphi} s\right) \\
& \text { if } u Q_{\varphi} t \text {, then } V(u, \varphi)=V(t, \varphi) .
\end{aligned}
$$

It is easy to note that if model $\mathfrak{M}$ satisfies the condition (c8), then it also satisfies the condition (c4). The following fact takes place:

3. If, for a given relevance relation, the conditions (c1), (c7) and (c8) are satisfied for propositional variables, the condition (c8) is satisfied for any formula.

This fact is easily proven inductively by the complexity of the formulas. Fact 3 , in a way, allows us to weaken the condition (c5). If a given contextual model $\mathfrak{M}$ satisfies the conditions (c1), (c7) and (c8) for propositional variables, formulas with the form $\left(\mathrm{T}^{R}\right)$ will be true formulas in $\mathfrak{M}$.

\section{Conclusion}

In the first part of the paper, we presented the basic thesis of epistemic contextualism and pointed out its selected modifications and extensions as well as similar positions (practical invariantism, contrastivism, relativism). Next, we highlighted the most important areas of discussion and explored the contextual anti-sceptical strategy as well as the context shifting argument for epistemic contextualism. This description led to the formulation of three postulates for the formalisation of epistemic contextualism: i) maintaining the deductive closure of knowledge, ii) maintaining the factivity of knowledge and iii) adopting the broadest possible concept of context that could take into account the various factors determining the epistemic standards identified in the literature. ${ }^{66}$

${ }^{66}$ Let us emphasise the following again: one may be an epistemic contextualist and not take into account any of these postulates. However, our approach does not exclude such a version of contextualism; it can be adapted to it. These postulates simply point to a widespread version 
In the formal part of the paper, we focused on the solutions proposed by Lihoreau and Rebuschi ${ }^{67}$ and Halliday ${ }^{68}$ In addition, we presented an analysis of epistemic contextualism on the basis of positional logic. It is worth noting that this approach refers to the epistemic operator relativised to a position representing the context. However, according to the analysis presented by Malinowski, Pietrowicz and Szalacha-Jarmużek, ${ }^{69}$ the knowledge operator can be relativised to a context understood as an ordered $n$-tuple wherein particular positions allow different kinds of basic contexts to be taken into account. Such modifications, as well as the proof theory of the analysed logics, may be the subject of future research on epistemic contextualism and positional logic.

\section{Acknowledgements}

The authors would like to thank Tomasz Jarmużek and the anonymous reviewers for all their remarks and suggestions.

\section{References}

Baumann Peter. 2008. "Contextualism and the Factivity Problem". Philosophy and Phenomenological Research 76, 3: 580-602.

Brueckner Anthony, Christopher T. Buford. 2009. "Contextualism, SSI and the Factivity Problem". Analysis 69, 3: 431-438.

Buckwalter Wesley. 2010. "Knowledge isn't closed on Saturday: A study in ordinary language". Review of Philosophy and Psychology 1, 3: 395-406.

Cappelen Herman, Ernie Lepore. 2003. "Context Shifting Arguments". Philosophical Perspectives 17: 25-50.

of contextualism that adopts the theses, which are relatively rarely challenged in epistemology and various factors that shape epistemic standards.

${ }^{67}$ Rebuschi, Lihoreau, "Contextual epistemic logic”, 305-335.

68 Halliday, "Epistemic logic, relevant alternatives, and the dynamics of context", 109-129.

${ }^{69}$ Malinowski, Pietrowicz, Szalacha-Jarmużek, "Logic of social ontology and Łośs operator": 239-258. 
Chellas Brian. 1975. "Basic conditional logic". Journal of Philosophical Logic 4: 133-153.

Chemla Emmanuel, Nat Hansen. 2013. "Experimenting on contextualism". Mind \& Language 28, 3: 286-321.

Cohen Stewart. 1987. "Knowledge, context, and social standards". Synthese 73, 1: 3-27.

Cohen Stewart. 1988. "How to be a fallibilist”. Philosophical Perspectives 2: 91-123.

Cohen Stewart. 2002. "Basic Knowledge and the Problem of Easy Knowledge". Philosophy and Phenomenological Research 65, 2: 309-329.

DeRose Keith. 1995. "Solving the sceptical problem". The Philosophical Review 104, $1: 1-52$.

DeRose Keith. 2009. The Case for Contextualism. Oxford: OUP.

DeRose Keith. 2017. The Appearance of Ignorance. Oxford: OUP.

Dretske Fred. 1970. "Epistemic operators". The Journal of Philosophy 67, 24: 10071023.

Egan Andy, John Hawthorne, Brian Weatherson. 2005. "Epistemic modals in context". In: Contextualism in Philosophy. Knowledge, Meaning, and Truth, eds. Gerhard Preyer, Peter Georg, 131-168. Oxford: OUP.

Goldman Alvin I. 1976. "Discrimination and Perceptual Knowledge". The Journal of Philosophy 73, 20: 771-791.

Halliday Wesley H. 2012. "Epistemic logic, relevant alternatives, and the dynamics of context". In: New Directions in Logic, Language and Computation, eds. Daniel Lassiter, Marija Slavkovik, 109-129. Berlin, Heidelberg: Springer.

Hawthorne John. 2004. Knowledge and lotteries. Oxford: Clarendon Press.

Hazlett Allan. 2010. "The Myth of Factive Verbs". Philosophy and Phenomenological Research 80, 3: 497-522.

Heller Mark. 1999. "The proper role for contextualism in an anti-luck epistemology". Philosophical Perspectives 13: 115-129.

Hiż Henryk. 1951. "Review: J. Los, Foundations of the methodological analysis of Mill's canons". Journal of Symbolic Logic 16: 58-59.

Jarmużek Tomasz. 2007. "Minimal logical systems with R-operator: Their meta-logical properties and ways of extensions". In: Perspectives on Universal Logic, eds. J. Bezieau, A. Costa-Leite, 319-333. Polimetrica Publisher.

Jarmużek Tomasz. 2018. On Sea Battle Tomorrow That May Not Happen. A Logical and Philosophical Analysis of the Master Argument. Berlin: Peter Lang.

Jarmużek Tomasz, Aleksander Parol. 2020. "On Some Language Extension of Logic MR: A Semantic and Tableau Approach”. Roczniki Filozoficzne 68: 345-366.

Jarmużek Tomasz, Andrzej Pietruszczak. 2004. "Completeness of minimal positional calculus". Logic and Logical Philosophy 13: 147-162.

Jarmużek Tomasz, Marcin Tkaczyk. 2015. Normalne logiki pozycyjne (Normal Positional Logics). Lublin: Towarzystwo Naukowe KUL. 
Jarmużek Tomasz, Marcin Tkaczyk. 2019. "Expressive Power of Positional Operator R: A Case Study in Modal Logic and Modal Philosophy". Ruch Filozoficzny LXXV, 2: 93-107.

Kallestrup Jesper. 2005. "Contextualism between Scepticism and Common-Sense". Grazer Philosophische Studien 69: 247-253.

Klonowski Mateusz, Krzysztof A. Krawczyk. 2019. "Problem wszechwiedzy logicznej. Krytyka nienormalnych światów i propozycja nowego rozwiązania” "“The problem of logical omniscience. The critique of non-normal worlds and the proposition of new solution"). Filozofia Nauki 27, 1: 27-48.

Lasonen-Aarnio Maria. 2017. "Contextualism and closure". In: The Routledge Handbook of Epistemic Contextualism, eds. Jonathan Jenkins Ichikawa, 156-167. London and New York: Routledge.

Lewis David. 1996. "Elusive knowledge". Australasian Journal of Philosophy 74, 4: 549-567.

Lechniak Marek. 1988. "Logika epistemiczna Jerzego Łosia a teoria racjonalnego zachowania" ("Epistemic logic of Jerzy Łoś and the theory of rational behaviour"). Roczniki Filozoficzne 26, 1: 79-91.

Lihoreau Franck, Manuel Rebuschi. 2014. "Reasoning about knowledge in context". In: Interdisciplinary Works in Logic, Epistemology, Psychology and Linguistics. Dialogue, Rationality, and Formalism, eds. Manuel Rebuschi, Martine Batt, Gerhard Heinzmann, Franck Lihoreau, Michel Musiol, Alain Trognon, 155-179. Cham, Heidelberg, New York, Dordrecht, London: Springer.

Łoś Jerzy. 1947. "Podstawy analizy metodologicznej kanonów Milla" ("Basics of methodological analysis of Mill's canons"). Annales Universitatis Mariae Curie-Skłodowska, 2.5. F: 269-301.

Łoś Jerzy. 1948. "Logiki wielowartościowe a formalizacja funkcji intensjonalnych" ("Multivalued logics and formalisation of intensional functions"). Kwartalnik Filozoficzny XVII, 1-2: 59-78.

MacFarlane John. 2005. "The assessment sensitivity of knowledge attributions". In: Oxford Studies in Epistemology. Vol. 1, eds. Tamar Szabo Gendler, John Hawthorne, 197-233. Oxford: OUP.

MacFarlane John. 2014. Assessment Sensitivity: Relative Truth and Its Applications. Oxford: OUP.

Malinowski Jacek, Krzysztof Pietrowicz, Joanna Szalacha-Jarmużek. 2020. "Logic of social ontology and Łośs operator". Logic and Logical Philosophy 29: 239-258.

Palczewski Rafał. 2014. Wiedza w kontekstach. T. I: Między pragmatyką a semantyką. Toruń: Wydawnictwo Naukowe UMK.

Palczewski Rafał. 2015. "O aletycznej naturze wiedzy" ("On the Alethic Nature of Knowledge”). Filozofia Nauki 23, 1: 99-145. 
Priest Graham. 2008. An Introduction to Non-Classical Logic. From If to Is. New York: Cambridge University Press.

Rebuschi Manuel, Franck Lihoreau. 2008. "Contextual epistemic logic”. In: Dialogues, Logics and Other Strange Things, eds. Cedric Degremont, Laurent Keiff, Helge Rueckert, 305-335. London: College Publications.

Rescher Nicholas. 1968. "Topological logic". In: Nicholas Rescher, Topics in philosophical logic, Dordrecht: D. Reidel Publishing Company, 229-249.

Rescher Nicholas, Alasdair Urquhart. 1971. Temporal Logic. Vienna: Springer.

Schaffer Jonathan. 2004. "From contextualism to contrastivism". Philosophical Studies 119, 1-2: 73-103.

Schaffer Jonathan. 2005. "Contrastive knowledge". In: Oxford Studies in Epistemology. Vol. 1, eds. Tamar Szabo Gendler, John Hawthorne, 236-271. Oxford: OUP.

Scott Dana. 1970. "Advice on modal logic". In: Philosophical Problems in Logic, ed. K. Lambert, 143-173. Dordrecht: Reidel.

Stanley Jason. 2005. Knowledge and Practical Interests. Oxford: Clarendon Press.

Suszko Roman. 1949. "Review: Jerzy Łoś, Many-valued logics and formalisation of intensional functions". Journal of Symbolic Logic 14: 64-65.

Tkaczyk Marcin. 2009. Logika czasu empirycznego (Logic of Physical Time). Lublin, Wydawnictwo KUL.

Tkaczyk Marcin, Tomasz Jarmużek. 2019. "Jerzy Łoś positional calculus and the origin of temporal logic". Logic and Logical Philosophy 28: 259-276.

Tkaczyk Marcin. 2013. "Negation in weak positional calculi". Logic and Logical Philosophy 22: 3-19.

Wright Georg von. 1951. An Essay in Modal Logic. Amsterdam, North-Holland Publishing Company.

Abstract: In the late 1940s, Jerzy Łoś published two works ${ }^{70}$ wherein he discussed logics with the realisation operator (later called positional logics). In these works, he investigated two interpretations of this operator: temporal and epistemic. In this article, we aim to develop and modify the epistemic interpretation so as to obtain a formalisation of epistemic contextualism, one of the most significant epistemological positions in contemporary times. According to this position, the logical value of epistemic sentences depends on contextually determined epistemic standards. We will demonstrate the advantage of such formalisation over previous attempts at the logical representation of epistemic contextualism.

Keywords: epistemic contextualism, positional logic, Łośs realisation operator, relevant alternatives, epistemic logic

70 See Jerzy Łoś, “Podstawy analizy metodologicznej kanonów Milla”, 59-78. 